Bolm Inst. oceanogr., S Paulo, 28(2):95-100, 1979

\title{
CONTRIBUIÇÃO AO ESTUDO DAS CORRENTES MARINHAS NA PLATAFORMA ENTRE CABO FRIO E CANANËIA*
}

\author{
AFRÂNIO RUBENS DE MESQUITA; JOÃO BATISTA DE ASSIS LEITE \& \\ REYNER RIZZO
}

Instituto Oceanogräfico da Universidade de São Paulo

\section{Synops is}

Current, temperature and salinity data from two sections and 13 days time series are analysed. Additional data from other efforts are sumarized with other contributions yielding a tentative winter surface circulation model of the area. From the summary, mechanisms of the upwelling at Cabo Frio are suggested.

\section{Introdução}

Aos trabalhos de Emílsson (1959; 1961) sobre a constituição e distribuição das massas d'água na costa sudeste do Brasil, que ressaltaram resultados relativos à descoberta da "ressurgência" na ārea de Cabo Frio $\left(23^{\circ} \mathrm{S} ; 42^{\circ} \mathrm{W}\right)$, seguiram-se vários estudos sobre o fenômeno na área e em āreas adjacentes, o que permitiu uma visão mais clara sobre a circulação e suas causas dinâmicas. Muitas questões, entretanto, permanecem ainda sem resposta, o que torna o tema aberto à especulação e à pesquisa.

0 objetivo desta nota é o de levantar hipóteses sobre a circulação de superfície durante os meses de inverno nas áreas costeiras entre Cananéia, Santos e Cabo Frio, e também examinar um modelo de circulação que possa, eventualmente, explicar, em parte, a ressurgência na área bastante restrita de Cabo Frio.

Este estudo se baseia nos resultados dos cruzeiros oceanográficos realizados a bordo do N/Oc. "Prof. W. Besnard", do Instituto Oceanográfico da USP, pelo Sub-Projeto Hidrodinâmica Costeira, FINEP, e em resultados e dados de vários pesquisadores que contribuiram ao conhecimento da área.

Os dados

São consideradas medidas de temperatura, salinidade e correntes, sob a forina de séries de tempo obtidas em estação fixa no ponto $\left(23^{\circ} 23^{\prime} \mathrm{S} ; 43^{\circ} 17^{\prime} \mathrm{W}\right)$ sobre a isóbata de $100 \mathrm{~m}$, durante o período de $17 / 07 / 78$ a $05 / 08 / 78$, bem como duas sec-

* Trabalho apresentado no 29 Encontro de Cientistas do Mar. Recife, 11-15 de dezembro de 1978, FINEP.

Publ. nọ 451 do Inst. oceanogr. da Usp. ções verticais obtidas no início e no fim do cruzeiro. Outros dados são referidos em Resultados e discussão.

As medidas de correntes foram feitas com instrumentos Hidrocean; detalhes destas medidas e outras, reduçãa dos dados e técnicas de amostragem são as mesmas usadas por Mesquita et al. (1977).

$\mathrm{Na}$ Figura 1 podem ser vistas as posições da estação fixa e das estações correspondentes às secções verticáis inicial e final.

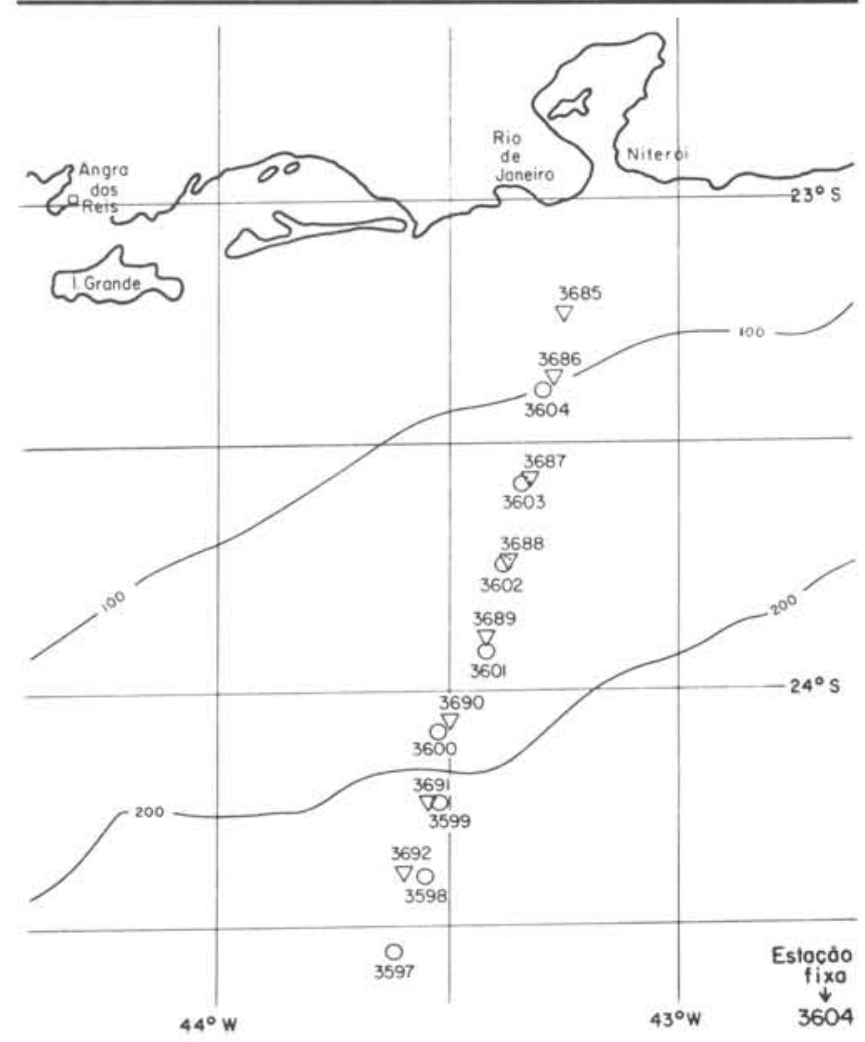

Fig. 1. Posicionamento das estações nas secções verticais.

o estações da secção vertical inicial

$\nabla \equiv$ estações da secção vertical final 
As Figuras 2 e 3 mostram as iistribuições de temperatura e salinidade nas duas secções verticais.

Foram realizadas observaçũes de correntes nas profundidades de $5,10,20$, $30,40,50,60,70,8 \mathrm{C}$ e $90 \mathrm{~m}$. A Figura 4 mostra as componentes $\mathrm{N}-\mathrm{S}$ da $\mathrm{c}$ rrente, sob a forma de isopletas para os dias 23 e $2 \frac{1}{4} / 07 / 78$.

Para o mesmo período são mostradas, na Figura 5, as isopletas de temperatura e, na Figura 6 , as de salinidade.

As médias das componentes N-S e E-O das correntes, em 300 horas de observação podem ser vistas na Figura 7 . Outros dados são referidos na secção seguinte.

\section{Resultados e discussão}

A secção vertical inicial (Fig. 2) mostra que águas da Corrente do Brasil, caracterizadas por um nücleo de $\mathrm{S}=$ $36,90^{\circ} \% \circ ; \mathrm{T}=23,5^{\circ} \mathrm{C}$, se encontravam, a princípio, sobre a borda da plataforma continental. Na seç̧ão final (Fig. 3), obtida 13 dias depois, elas apresentavam-se mais afastacids da crsta, provavelinente devido à intensificação dos ventos ncrdeste, registrados nos ültimos diás do período de observação ein estação fixa, observando-se. entao, apenas o resultado de sua influência.

Um aspecto notāvel da secção inicial, é a aparente "quebra" das äquas de fundo $\left(\mathrm{T} \leqslant 15^{\circ} \mathrm{C}: \mathrm{S} \leqslant 35,50^{\circ} \%\right.$ o) em dois segmentos; um localizado mais ao largo e ao funco e o outro que, em conscqüência da quebra, ficou aparentemente "entancado" entre cs águas da Corrente do Brasil e a costa.

Essa situação não se repete na secção final onde, ao invés do "entancamento", observa-se una irfiltração das águas tropicais (da Corrente do Brasil) entre as profundidades ue $30 \cong 70 \mathrm{~m}$. No fundo, a uma profundidade maior que $70 \mathrm{~m}$, 1rcalizı-se a massa de águıs mais frias e menos salinas ( $\mathrm{T} \leqslant 15^{\circ} \mathrm{v} ; \mathrm{S} \leqslant 35,5^{\circ} \%$ o) que, com o afastamento das águas tropicais em relação à costa, voltam a formar um corpo único.
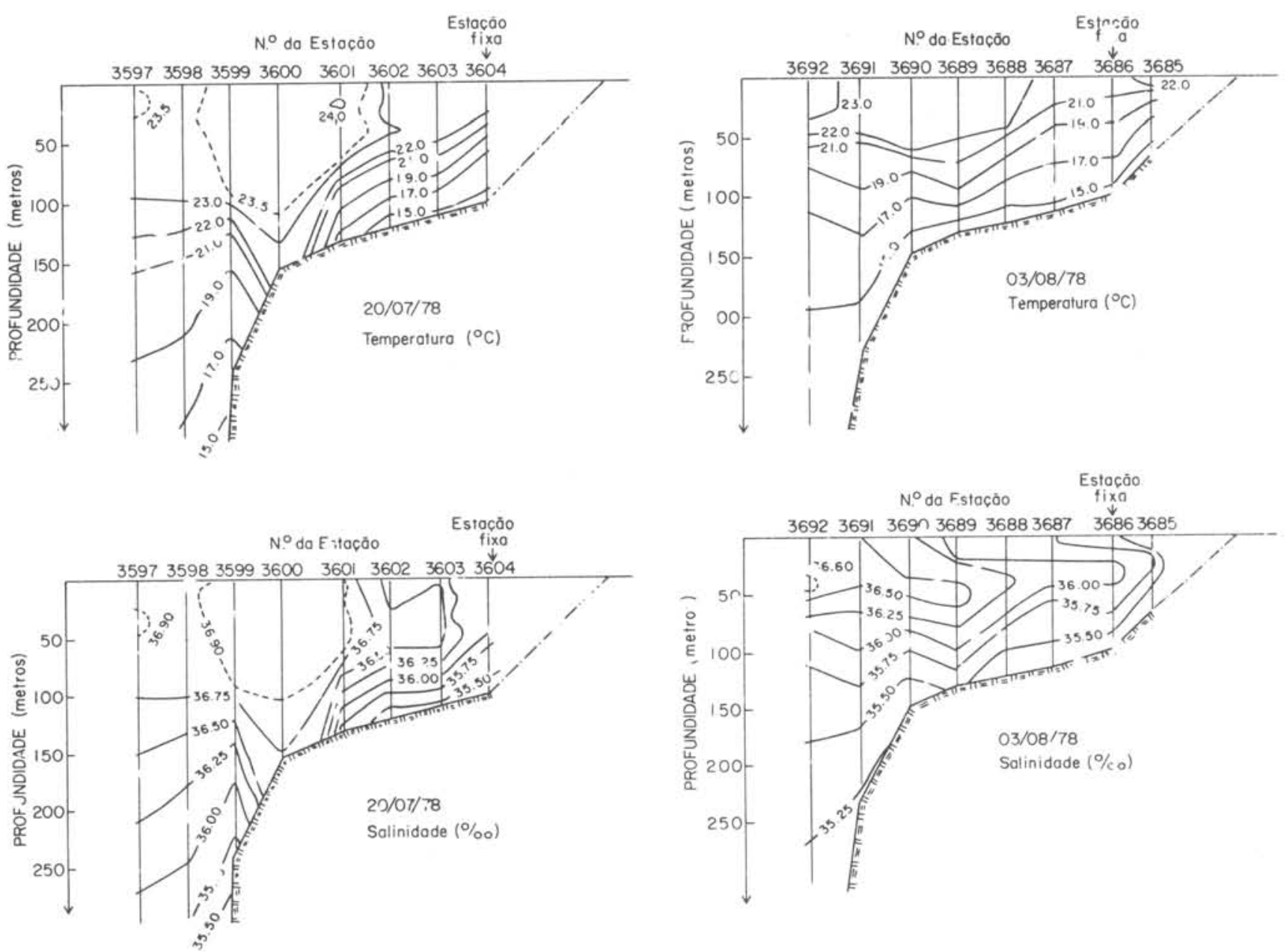

Fig. 2. Isolinhas de temperatura e salinidade para a secção vertical inicial.

Fig. 3. Isolinhas de temperatura e salinidade para a secção vertical final. 


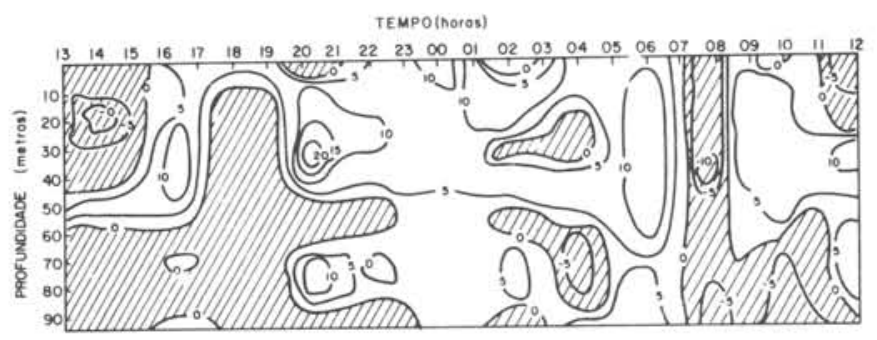

Fig. 4. I sopletas de correntes - componente norte-sul (em $\mathrm{cm} / \mathrm{s}$ )

Período de observação - 13 horas de $23 / 07 / 78$ às 12 horas de 24/07/78.

Hachuras: direção para sul.

TEMPO(noros:

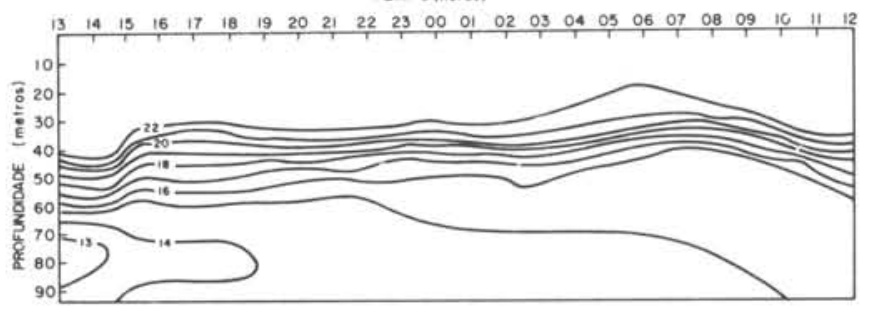

Fig. 5. Isopletas de temperatura $\left(\mathrm{em}^{\circ} \mathrm{C}\right)$ Período de observação - 13 horas de 23/07/78 às 12 horas de $24 / 07 / 78$.

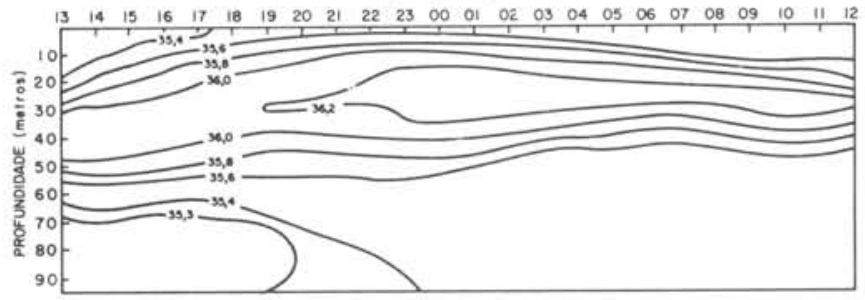

Fig. 6. I sopletas de salinidade (em $\%$ o) Período de observação - i3 horas de $23 / 07 / 78$ às 12 horas de $24 / 07 / 78$.

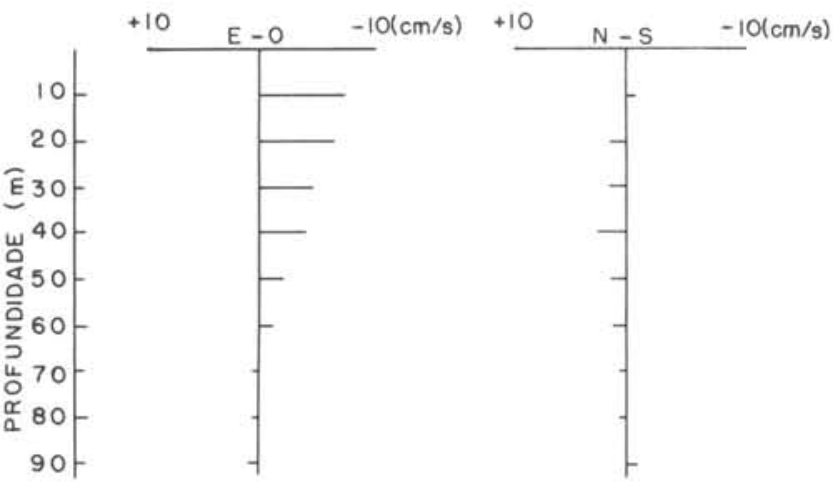

Fig. 7. Mëdias de 200 horas de medidas de correntes em värias profundidades. Na superfície, as médias para as componentes E-O e N-S são, respectivamente, $-11,91 \mathrm{~cm} / \mathrm{s}$ e $0,05 \mathrm{~cm} / \mathrm{s}$. Atē 60 metros, hä predominância de movimento no sentido oeste.

Uma característica comum às secções, é a variação alternada de regiões em que as isolinhas se encontram próximas umas das outras com regiões em que elas se encontram mais afastadas entre si. Isto pode ser observado ao longo das camadas de 0 a $200 \mathrm{~m}$ e de 0 a $100 \mathrm{~m}$ de profundidade, próximo à costa, tanto na distribuição de temperatura como na de salinidade.

Essa variabilidade parece estar associada à distribuição irregular das isopletas de correntes mostradas na Figura 4. A coluna d'água de 0 a $90 \mathrm{~m}$ é, aparentemente, dominada por vórtices, cuja direção de propagação é irregular e cujas dimensões são de difícil avaliação com os presentes dados.

Estes aspectos são menos visíveis nas isopletas de temperatura e salinidade (Figs 5 e 6) que, exceto variações a longo termo, não mostram um claro movimento ascendente ou descendente dos valores de $\mathrm{T}$ e $\mathrm{S}$ como conseqüência dus vórtices.

0 çráter rotatório a longo termo do sistema de correntes é, entretanto, caracterizado na Figura 7 , onde são apresentadés as médias de 300 horas de observações .

A $100 \mathrm{~m}$ de profundidade, a corrente média tem direção levemente sudoesce, passando a noroeste e atingind um máximo, ı.essa direção, a $40 \mathrm{~m}$. Entre 20 e $60 \mathrm{~m}$, como pode ser observac'o ias F'guras 3 e 6 , encontra-s@ uma "língua" d'água proveniente da Corrente do Brasil. De $i 0$ a $00 \mathrm{~m}$, o fluxo médio muda para a direção nordeste e depois sudeste, sendo, no entanto, muito mais fraco que nas camades mais à superfície. As guas de fundo são menos salinas e mais frıas, u 
que caracteriza, de acordo com Emílsson (1961), uma massa de Água Sub-Tropical.

Os presentes resultados, aliados a contribuições de outros pesquisadores, permitem levantar hipóteses sobre o sistema de circulação mais provāvel da ārea.

A Figura 8 mostra o esquema de circulação mais provável durante os meses de inverno, resultante da análise comparativa dos dados e/ou resultados obtidos por várics pesquisadores.

As setas em linha cheia indicam a direção das currentes predominantes, enquanto que as em 1 inha tracejada indicam a direção das correntes rão-predominantes. As setas curvilíneas cheias, com sentido anti-horário, indicam a predominância de correntes rotatórias com origem nas marés.

A área hachurada, entre as isóbatas de 100 e $200 \mathrm{~m}$, indica, aproximadamente, uma região de intensificação das águas da Corrente do Brasil. As setas curvilíneas cheias, com sentido horário, indicam correntes rotatórias, com esse sentido, por causa do cisalhamento lateral entre as ágias da Corrente do Brasil e as águas costeiras localizadas sobre a plataforma continental.

As āreas assinalajas com as letras A, $B, C, D, E, F$ e $G$ são regiões onde a circulação tem aspectos aparentemente bem definilos.

$\mathrm{Na}$ região $\mathrm{A}$, de acordo com o que sugerem as medidas realizadas por Johannenssen (1968) e por Inostroza et al. (1976), predominam as águas da Corrente do Brasil, fluindo na direção sudoeste. Parte dela invade a plataforma continental, em regiões com profundidade inferior a $100 \mathrm{~m}$, enquanto que a parte principal, junto à costa, flui de modo a acompanhar as isóbatas de $100-200 \mathrm{~m}$.

Nessa mesma região, Johnnenssem (op.cit.) registra também a presença de correntes rotatórias de maré com sentido anti-horário.

Na região B,observa-se uma abrupta mudança na direção das isóbatas de 100 e $200 \mathrm{~m}$. De acordo com o que sugerem os dados de Signorini (1978) e Inostruza et al. (op.cit.) as águas da Corrente do Brasil, por efeito da inércia, mantêm seu fluxo na direção da região $C$ e, nessa

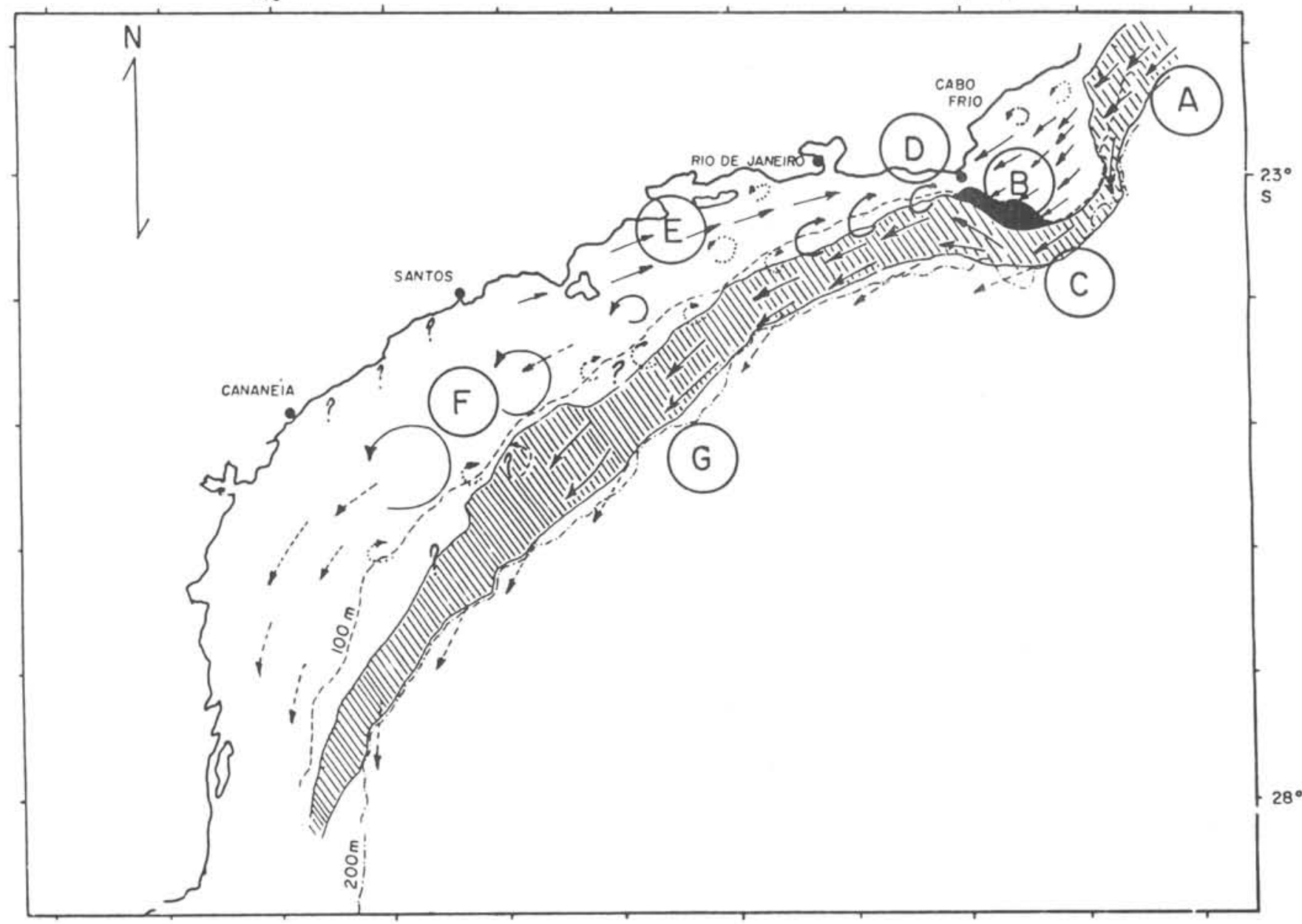

Fig. 8. Provävel circulação de inverno. 
região, portanto, afastam-se do talude continental. Is to tende a criar, na região B, uma zona de baixa pressão, favorecendo o afloramento da Āgua Sub-Tropical, a qual, nessa região, flui no sentido nordeste, em profurdidades intermediárias, como assinala Emílsson (1959).

Nessas condições, a. dimensões dessa zona de baixa pressão são bastante influenciāveis pelas intensificações da Corrente do Brasil, as quais, por sua vez (Silva, 1976), são sensíveis aos ventos predominantes na área.

Devido à tendência de acoupanhur as isóbatas de 100-200 m, águas da Corrente do Brasil, após se afastarem delas por inércia, na região $C$, defletem para oeste, fluindo en direção à região D. Nessa região, encontrando as águas costeiras locais, dão origem a vórtices, com giro no sentido horário, que tendem a intensificar as correntes costeiras, com sentido nordeste, predominantes entre Santos e Ric de Janeiro nos meses de inverno.

A existếncia de vōrtices na regic̃o D pode ser inferida com base nos dados de Ikeda et al. (1974). A presença de correntes costeiras, com sentido nordeste, na regicáo $E$, é mostrada por

Luedemann (1979) e por Matsuura (1975), empregando corpos-de-deriva. Johannens sen (1968) registra, nessa mesma área, a presença de correntes rotatórias de maré com sentido anti-horário.

$\mathrm{Na}$ região $\mathrm{F}$, observa-se a predominância de correntes rctatórias de maré com sentido anti-horáris, superpostas a uma corrante de menor intensidade fluindo no sentido sudoeste (Mesquita et al., 1977)

Nas regiões assinaladas com pontos de interrogação, a circulação real rıão é bem conhecida.

Na região $G$, é provável a existência de deslocamentos das águas para a esquerda, compensando o afluxo das águas costeiras que se 1 ncorporam ao sistema de circulação da Corrente do Brasil.

A análise dos diferentes dados e resultados apresentados rermite. pois, sugerir dois mecanismos parà a circulação na ärea de Cabo Frio.

De acordo com eles, parece claro q 1e a aproximação das Águas Tropi ‘ais, levadas pela Corrente do Brasil no ponto $\left(23^{\circ} 23^{\prime} \mathrm{S} ; 42^{\circ} 17^{\prime} \mathrm{W}\right)$, pode produzir um efeito de "entarcamento" das águas costeiras, seguidas de arrastamento dessas águas pela Corrente do Brasil, através de vörtices com sentido anti-horário. Dadas as características topográficas da área, onde o talude continental se aproxima cerca de 25 mn da costa, é muito provável que, em consequência, ocorra na área um efeito de "sucção", com máximo em Cabo Frio e que, além de ativar a ressurgência da área, possa ainda ser respcnsável pela existência de correntes costeiras durante os meses de inverno, no limite até $30 \mathrm{mn}$ da costa, com direção Santos-Cabo Frio. 0 outro mecanismo está relacionado com a área B na Figura 8. A existência de Āguas Sub-Tropicais com fluxo em direção nordeste, em profundidades baixas como as observadas entre 70 e $90 \mathrm{~m}$ no ponto acima mencionado, indica que uma causa dinâmica as mantém próximas à superfície e ainda as impulsiona em direção nordeste. E muito prováve1, pois, que efeitos inerciais e geostróficos das águas da Corrente do Brasil, jā mencionados, devidos à abrupta mudança de direção das isóbatas 100 e $200 \mathrm{~m}$, na latıtude de Cabo Frio, sejam causas, entre outras, que possam ser levantadas para a explicação do fenômeno.

\section{Conclusões}

a) Resultados de medidas de coŕrentes no ponto $\left(23^{\circ} 23^{\prime} \mathrm{S} ; 42^{\circ} 17^{\prime} \mathrm{W}\right)$ indicam a existência de corıentes de pequena intensidade a $90 \mathrm{~m}$ de profundidade, que fluem na direção nordeste em oposição ao fluxo da Corrente do Brasil.

b) A aproximação das Águas Tropicais, 1evadas pela Corrente do Brasil em direção SW, no ionto $\left(23^{\circ} 23^{\prime} \mathrm{S} ; 42^{\circ} 17^{\prime} \mathrm{W}\right)$ pode produzir um efeito de "entancamento" das águas costeiras, seguidas de arrastamento dessas águas pela Corrente do Brasil, através de vórtices no sentido horário. Conseqüente ao arrastamento, um efeito de "sucção" é sugerido, com máximo na área de Cabo Frio e que pole ser responsáve1 pela existência de correntes costeiras, durante os məses de invarno, no limite de até $30 \mathrm{mn}$ fora da costa, com direção de Santos a Cabo Frio.

c) A existência de Āguas Sub-Trnpicais com fluxo em direção nordeste no ponto $\left(23^{\circ} 23^{\prime} \mathrm{S} ; 42^{\circ} 17^{\prime} \mathrm{W}\right)$ entre 70 e $90 \mathrm{~m}$ sugere que efeitos inerciais e/ou geostróficos provocados pelas características topográficas a este de Cábo Frio, com a ahrupta mudança de direção do talude continental, ao longo do qual flui a Corrente do Brasil, sejam mecanismos que mantêm tais águas próximás à s.uperfície durante todas as estações do ano. 


\section{figradecimentos}

À FINEP, pelo auxílio financeiro concedido.

Ao Diretor do IOUSP, Dr. André Ricciardi Cruz, pelo apoio entusiasta ao programa.

Ao Dr. Argeo Magliocca, pelas críticas e discussões construtivas durante o preparo do manuscrito.

\section{Bibliografia}

EMILSSON, I. 1959. Alguns aspectos físicos e químicos das águas marinhas brasileiras. Ciênc. Cult., S Paulo, $11(2): 44 \cdots 54$.

1961. The shelf and coastal waters off southern Brazil. Bolm Inst. oceanogr., S Paulo, 11(2):101-112.

IKEDA, Y.; MIRANDA, L. B. de \& ROCK, N. J. 1974. Observations on stages of: upwelling in the region of Cabo Frio (Brazil) as conducted by continuous surface temperature and salinity measuremente. Bolm Inst. oceanogr., S Paulo, 23:33-46.

INOSTROZA, V. H.; ALMEIDA, E. G. \& MASCARENHAS Jr., A. da S. 1976. Expedição oceanográfica SEREMAR IV. Relat. INPE-825-NTE $; 049$, : 1-142.

JOHANNENSSEN, O. M. 1968. Note on some hydrographical and current observations from three positions on the Brazilian shelf in the region of Cabo Frio-Santos 1966. Contrçoes Inst. oceanogr. Univ. S Paulo, sér. Ocean. fís., (10): $1-8$.
LUEDEMANN, E. F. 1979. Contribuição ao estudo das correntes de superfície sobre a plataforma continental do Estado de São Paulo, Brasil (Lat. $24^{\circ} 00^{\prime} \mathrm{S}-25^{\circ} 10^{\prime} \mathrm{S}$ até Jong. $\left.45^{\circ} 40^{\prime} \mathrm{W}\right)$. Bolm Irist. oceanogr., S Paulo, 28(2): 47-53.

MATSUURA, Y. 1975. A study of surface currents in the spawning area of Brazilian sardine. Bolm. Inst. oceanogr., S Paulo, 24:31-44.

MESQUITA, A. R. de; SOUZA, J. M.; TUPINAMBA, P. M.; WEBER, R.; FESTA, M. \& LEITE, J. B. A. 1977 . Correntes rotatórias e variabilidade do campo de massa na plataforma do Estado de São Paulo (Ponto: $25^{\circ} \mathrm{S} ; 46^{\circ} \mathrm{W}$ ). Relc.. Cruzeiros, sér. N/Cc. "Prcf. W. Besnará", Inst. oceanogr. Univ. S Paulo, (3):1-27.

SIGNCRINI, S. R. 1978. On the circuiation and the volume transport of the Brazil Current between the Cape of São Tomé and Guanabara Bay. DeepSea Res., 25(5): 481-490.

SILVA, P. de C. M. da \& MENDONÇA, C. F. 1976. A ressurgência em Cabo Frio (II); significação física da charneira. Publções Inst. pesq. Mar., (99): $1-68$.

(Recebido em 21/dezembro/197f) 